\title{
To study the effectiveness of self-instructional module on knowledge and selected outcome among women undergoing hysterectomy in a tertiary care hospital in South India
}

\author{
Elgi MC*, Lekha Viswanath
}

\begin{abstract}
Department of Obstetrics and Gynaecological Nursing, Amrita College of Nursing, Amrita Vishwa Vidyapeetham
\end{abstract} Health Science Campus, Amrita Institute of Medical Sciences, Kochi-41, Kerala, India

Received: 26 October 2016

Revised: 24 October 2016

Accepted: 15 November 2016

\author{
*Correspondence: \\ Dr. Elgi MC, \\ E-mail: elgi.arun@gmail.com
}

Copyright: () the author(s), publisher and licensee Medip Academy. This is an open-access article distributed under the terms of the Creative Commons Attribution Non-Commercial License, which permits unrestricted non-commercial use, distribution, and reproduction in any medium, provided the original work is properly cited.

\begin{abstract}
Background: Hysterectomy is a one of the major operations of surgical treatment in Gynecology. The purpose of the study was to assess the effectiveness of Self -Instructional Module (SIM) on knowledge and selected outcome among women undergoing hysterectomy at a tertiary care hospital Kochi.

Methods: An experimental approach with a pretest-posttest control group design was used for the study. Forty women posted for hysterectomy were selected by convenience sampling technique. First 20 samples were allotted to experimental group and second 20 to the control group to avoid data contamination. SIM was given to the women in the experimental group after the pretest and post-test of both group was done on the fourth post-operative day. The socio-demographic and clinical data were collected by a semi-structured interview. A semi structured questionnaire was used to assess the pretest and posttest knowledge. The selected outcomes were measured using a ten point visual analogue scale in the fourth postoperative day. Data analysis was done by using descriptive and inferential statistics.

Results: The findings of the study revealed that the pre-test level of knowledge among experimental group was average for $13(65 \%)$, and poor for seven (35\%), whereas in post-test $12(60 \%)$ subjects had good knowledge and eight $(40 \%)$ had average knowledge. The mean post-test score of knowledge in the experimental group $(19.95+$ $3.268)$ is higher than the mean pre-test score of knowledge $(10.80+3.847)$ and the post-test score of control group $(9.5+4.2)$. These differences in the means were significant at $\mathrm{P}<0.001$. The mean score of all the selected outcomes were less in the experimental group than the control group. The difference in mean score was significant at $p<0.001$ in variable like pain, head ache, abdominal discomfort, insomnia, fatigue, anxiety and at $\mathrm{P}<0.05$ level in variables like pain on surgical site, pain on back, pain on abdomen.

Conclusions: Based on the major findings of the study, it was concluded that the self-instructional module on hysterectomy was effective in improving the knowledge of subjects and they felt it more useful in identifying the possible post-operative problems like pain on abdomen, surgical site pain, head ache, abdominal discomfort, insomnia, fatigue and anxiety. And take necessary steps to prevent it. SIM was effective as they could read and clear their doubts at their own place. More over the subjects experienced minimal problems associated with the surgery and subjects verbalized that they felt more comfortable to ask their doubts during the time of post assessment.
\end{abstract}

Keywords: Hysterectomy, Knowledge, Self-instructional module, Selected outcome 


\section{INTRODUCTION}

Hysterectomy is the surgical removal of uterus and its surrounding structure. ${ }^{1}$ Nowadays hysterectomy is the common procedure performed in the gynaecological area which aids in the reduction of many of the gynaecological problems. As per WHO data base in 2016, an estimated 15, 40000 women underwent hysterectomy in the world, making hysterectomy the most common non-pregnancy related major surgery performed on women. Hysterectomy is most commonly performed on women between 40 to 45 years of age and by age 65 approximately $37 \%$ to $39 \%$ of women have under gone this procedure. ${ }^{2}$

The first hysterectomy was performed by Charles Clay in November 1843.It was performed to remove large myomatous uterus .The operation was successful however the patient died on the fifteenth postoperative day. Massachusetts achieved the first successful abdominal hysterectomy although again the diagnosis was wrong. Vaginal hysterectomy dates back to ancient times. The procedure was performed by Soranus of Ephesus 120 years after the birth of Christ. Reports on the procedure used in the middle Ages for the extirpation of an inverted uterus indicate that the patients rarely survived. In the early hysterectomies, the patients usually died of complications like hemorrhage, peritonitis, and exhaustion. $^{3}$

The indications for hysterectomy are uterine fibroid, dysfunctional uterine bleeding, endometriosis, cancer of uterus, ovary, cervix, chronic pelvic pain, obstetrical hemorrhage, uterine prolapse, leiomyoma etc. ${ }^{4}$ The peak age of hysterectomy in women is 40-60 years. Traditionally, hysterectomies have been performed using a technique known as total abdominal hysterectomy (TAH). However, in recent years, two less-invasive procedures have been developed: i.e. vaginal hysterectomy and laparoscopic hysterectomy. ${ }^{5}$ A hysterectomy is generally very safe, but as in any other major surgery hysterectomy also comes with the risk of complications. Risks associated with an abdominal hysterectomy include blood clots, infection, excessive bleeding, adverse reaction to anesthesia etc. Sometimes it may be associated with damage to urinary tract, bladder, rectum or other pelvic structures, which may require further surgical repair. ${ }^{6}$

Hysterectomy is associated with many short term and long term complications. A retrospective study was conducted among 660 women on complications after hysterectomy in USA. About $58 \%$ of all women who had the surgery were unable to return to previous work activities and $43 \%$ were unable to return to work at all. Hormone imbalance and diminished hormone levels cause $75 \%$ of women post-hysterectomy to lose sexual desire, $66 \%$ to lose sexual arousal, $54 \%$ to lose sexual sensation and $53 \%$ suicidal thoughts associated with post hysterectomy depression. About $50 \%$ women have chance of suffering from ovarian failure within 5 years of surgery if ovaries are left in surgery. Nearly $50 \%$ of women experienced menopause-like symptoms such as hot flashes, mood swings and dry vagina post hysterectomy, necessitating hormone replacement therapy. ${ }^{7}$ Hysterectomy is associated with many problems in the immediate and early post-operative period also. A descriptive study conducted among 60 women in the first week after hysterectomy shows that all of them experienced severe pain $(100 \%)$ in the first day, moderate pain on second day and on third day $11.7 \%$ experienced moderate pain and $88.3 \%$ had mild pain. On the first and second day clients who had total abdominal hysterectomy reported more pain than other two groups. Other post operative problem were fatigue, abdominal discomfort, anorexia, sleep disturbance due to pain etc. ${ }^{8}$

Creating awareness regarding these complications in terms of management and preventive measures helps in reducing the severity of the problems experienced. Preoperative teaching is an effective way of communicating information on identified patient's need, there by rendering care on these areas which aid in relief from postoperative problems, quick recovery and improve fitness. Preparing the women undergoing hysterectomy preoperatively is beneficial in improving their self-care activities following surgery which may in turn improve their post-operative outcome.

The purpose of the present study is to evaluate the effectiveness preoperative teaching on women undergoing hysterectomy. Self-instructional module was selected as the method to impart knowledge considering the ease of use as well as its use as a reference for selfcare on a long term basis. A self-instructional module was prepared for the women undergoing hysterectomy based on the findings of the need assessment studies conducted in the same setting. The present study is designed to investigate the effectiveness of SIM on knowledge and selected outcome among women undergoing hysterectomy.

\section{METHODS}

An experimental approach was used for the study. The study was conducted in the maternity unit of a tertiary care hospital in Kochi, Kerala, South India. Ethical clearance was obtained from the institutional ethical committee prior to data collection. The period of data collection was from 06-02-2016 to 01-04-2016. The women posted for hysterectomy were identified from the outpatient department. Their criteria for inclusion in the study were determined by interviewing and reviewing the records. The inclusion criteria are Age between 35 -60 years, the patient undergoing both abdominal and vaginal hysterectomy, the patient who are available at the time of data collection, who can read and write Malayalam or English and who are willing to participate in the study. The exclusion criteria are who had undergone other gynaecological surgery and women with gynaecological 
cancer. All the women undergoing hysterectomy who met the sampling criteria were selected for the study as a sample of convenience. Informed consent was obtained from the participants after explaining the purpose of the study. First twenty women were allocated to the control group and next twenty to the experimental group in order to avoid data contamination.

The socio-demographic and clinical data were collected using a semi-structured interview schedule. The pretest assessment of knowledge was done in the experimental group using semi structured questionnaire in the outpatient department. SIM was administered to the women in the experimental group after the pretest and were asked to read it at home. The instructions for using the SIM were also explained. The post -test assessment of knowledge and selected outcome was done on the fourth post-operative day in both experimental and control group. A ten point visual analogue rating scale was used to assess the selected outcome.

The data collected for the study are analysed by appropriate descriptive statistics and inferential statistics. Frequency and percentage is used to analyse the background information, knowledge and selected outcome. Mean percentage and standard deviation is used to describe the knowledge and selected outcome. T test was used to compare the knowledge and selected outcome.

\section{RESULTS}

\section{Sample characteristics}

The socio demographics data were described in the table 1.The demographics variables are age, marital status, education, occupation, area of residence, religion, type of delivery and source of information on hysterectomy.

\section{Effect of SIM on the level of knowledge regarding hysterectomy}

Comparison of mean pre-test and post-test scores of knowledge among experimental group

In the pre-test $13(65 \%)$ of the women with in the experimental group had average knowledge and 7 (35\%) had poor knowledge, where as in the post- test $12(60 \%)$ had good knowledge and $8(40 \%)$ had average knowledge.

The mean post- test score of knowledge in the experimental group $(19.95 \pm 3.268)$ is higher than the mean pre- test score of knowledge $(10.80 \pm 33.847)$. The difference in the mean is significant at $\mathrm{p}<0.001$ (Table 2).

Comparison of mean post-test scores of knowledge between experimental and control group
The comparison of mean post-test scores of knowledge between experimental and control group using independent T-test. This shows that the mean post-test score of knowledge among experimental group (19.95 \pm $3.268)$ is higher than the control group $(9.5 \pm 4.224)$. The difference between the post-test level of knowledge score shows significance difference at $\mathrm{p}$-values is less than 0.001 (Table 3).

Table 1: Distribution of subjects based on socio demographic variables $(n=40)$.

\begin{tabular}{|c|c|c|c|c|}
\hline \multirow[t]{2}{*}{$\begin{array}{l}\text { Demographic } \\
\text { variable }\end{array}$} & \multicolumn{2}{|c|}{$\begin{array}{l}\text { Control } \\
\text { group }(n=20)\end{array}$} & \multicolumn{2}{|c|}{$\begin{array}{l}\text { Experimental } \\
\text { group }(n=20)\end{array}$} \\
\hline & $\mathbf{F}$ & $\%$ & $\mathbf{F}$ & $\%$ \\
\hline \multicolumn{5}{|l|}{ Age in years } \\
\hline $\begin{array}{l}\text { Less than } 35 \\
\text { years }\end{array}$ & 1 & 5 & 1 & 5 \\
\hline $35-45$ years & 5 & 25 & 5 & 25 \\
\hline $45-55$ years & 10 & 50 & 8 & 40 \\
\hline Above 55 years & 4 & 20 & 6 & 30 \\
\hline \multicolumn{5}{|l|}{ Marital status } \\
\hline Married & 20 & 100 & 19 & 95 \\
\hline Unmarried & - & - & 1 & 5 \\
\hline Divorced & - & - & - & - \\
\hline \multicolumn{5}{|l|}{ Education } \\
\hline Primary education & 10 & 50 & 1 & 5 \\
\hline $\begin{array}{l}\text { Secondary } \\
\text { education }\end{array}$ & 1 & 5 & 10 & 50 \\
\hline Diploma & 8 & 40 & 3 & 15 \\
\hline $\begin{array}{l}\text { Degree/Post } \\
\text { graduate }\end{array}$ & 1 & 5 & 6 & 30 \\
\hline \multicolumn{5}{|l|}{ Occupation } \\
\hline Working & 10 & 50 & 5 & 25 \\
\hline Non-working & 10 & 50 & 15 & 75 \\
\hline \multicolumn{5}{|l|}{ Area of residence } \\
\hline Town & 9 & 45 & 4 & 20 \\
\hline Village & 11 & 55 & 16 & 80 \\
\hline \multicolumn{5}{|l|}{ Religion } \\
\hline Hindu & 11 & 55 & 17 & 85 \\
\hline Christian & 8 & 40 & 2 & 10 \\
\hline Muslim & 1 & 5 & 1 & 5 \\
\hline Others & - & - & - & - \\
\hline \multicolumn{5}{|l|}{ Type of delivery } \\
\hline Normal delivery & 13 & 65 & 10 & 50 \\
\hline LSCS & 7 & 35 & 10 & 50 \\
\hline \multicolumn{5}{|c|}{ Source of information on hysterectomy } \\
\hline Television & 5 & 25 & 4 & 20 \\
\hline Health worker & 8 & 40 & 5 & 25 \\
\hline Friends & 6 & 30 & 11 & 55 \\
\hline Newspaper & 1 & 5 & - & \\
\hline
\end{tabular}


Table 2: Comparison of the mean pre-test and posttest knowledge score among experimental group $(\mathbf{n}=\mathbf{2 0})$.

\begin{tabular}{|c|c|c|c|c|}
\hline \multirow[t]{2}{*}{ Groups } & $\begin{array}{l}\text { Scores of } \\
\text { knowledge }\end{array}$ & df & \multirow[t]{2}{*}{$\begin{array}{l}\text { T- } \\
\text { value }\end{array}$} & \multirow[t]{2}{*}{ p-value } \\
\hline & $\begin{array}{l}\text { Mean standard } \\
\text { deviation }\end{array}$ & & & \\
\hline Pre-test & 10.803 .847 & & & \\
\hline Post-test & 19.953 .268 & 19 & 11.597 & $\mathrm{p}<0.001^{*}$ \\
\hline
\end{tabular}

*Significant at the level of 0.001

\section{Comparison of selected outcome between experimental and control group}

In the presented study selected outcome refers to the problems experienced by the women after hysterectomy namely pain, headache, fatigue, anxiety, insomnia, and abdominal discomfort, which is measured by ten point visual analogue rating scale.

Table 3: Comparison of mean post-test scores of knowledge between experimental and control group $(n=40)$.

\begin{tabular}{|c|c|c|c|c|c|}
\hline \multirow[t]{2}{*}{ Groups } & & Post-scores of knowledge & df & \multirow[t]{2}{*}{ T-value } & \multirow[t]{2}{*}{ p-value } \\
\hline & & Mean standard deviation & & & \\
\hline Experimental & 20 & 19.953 .268 & & & \\
\hline Control & 20 & $9.5 \quad 4.224$ & 38 & 8.75 & $\mathrm{p}<0.001^{*}$ \\
\hline
\end{tabular}

*Significant

Table 4: Comparison of mean score of selected outcome between experimental and control group $(n=40)$.

\begin{tabular}{|c|c|c|c|c|c|c|}
\hline Selected outcomes & Group & $\mathbf{N}$ & Mean & SD & T value & p value \\
\hline & Experimental & 20 & 3.1 & 1.86 & 2.951 & $0.003^{*}$ \\
\hline Pain on surgical site & Control & 20 & 5.6 & 2.87 & & \\
\hline \multirow[t]{2}{*}{ Pain on back } & Experimental & 20 & 1.25 & 1.62 & 1.259 & 0.208 \\
\hline & Control & 20 & 2.65 & 3.33 & & \\
\hline \multirow[t]{2}{*}{ Pain on abdomen } & Experimental & 20 & 1.2 & 1.01 & 2.267 & $0.023 *$ \\
\hline & Control & 20 & 2.6 & 2.28 & & \\
\hline \multirow[t]{2}{*}{ Headache } & Experimental & 20 & 0.8 & 1.2 & 4.23 & $<0.001 *$ \\
\hline & Control & 20 & 5.2 & 3.24 & & \\
\hline \multirow[t]{2}{*}{ Abdominal discomfort } & Experimental & 20 & 2.25 & 2.45 & 5.175 & $<0.001 *$ \\
\hline & Control & 20 & 8.45 & 1.76 & & \\
\hline \multirow[t]{2}{*}{ Insomnia } & Experimental & 20 & 2.6 & 1.64 & 5.18 & $<0.001 *$ \\
\hline & Control & 20 & 8.2 & 1.85 & & \\
\hline \multirow[t]{2}{*}{ Fatigue } & Experimental & 20 & 2.2 & 2.31 & 4.606 & $<0.001 *$ \\
\hline & Control & 20 & 6.85 & 2.18 & & \\
\hline \multirow[t]{2}{*}{ Anxiety } & Experimental & 20 & 1.8 & 1.88 & 4.407 & $<0.001 *$ \\
\hline & Control & 20 & 6.4 & 2.62 & & \\
\hline
\end{tabular}

*Significant $>2.7$ T38 $<2.75$

The mean score of all the selected outcomes were less in the experimental group than the control group. The difference in mean score was significant at $\mathrm{p}<0.001$ in variable like head ache, abdominal discomfort, insomnia, fatigue, anxiety and at p0.05 level in variables like pain on surgical site, pain on back, pain on abdomen (Table 4).

\section{DISCUSSION}

In order to identify the effect of SIM on the knowledge of women undergoing hysterectomy the pretest and post- test knowledge score of the experimental group was compared using paired t-test. The post test score of the experimental and control group was also compared using independent sample t-test. In the pre-test $13(65 \%)$ of the women with in the experimental group had average knowledge and $7(35 \%)$ had poor knowledge, where as in the post-test $12(60 \%)$ had good knowledge and $8(40 \%)$ had average knowledge. The mean post- test knowledge score $(19.95 \pm 3.268)$ of the experimental group was significantly higher than their pre-test score $(10.80 \pm$ $3.487)$ as well as the post test score of the control group $(9.5 \pm 4.224)$. 
An experimental study conducted on the effectiveness of a structured teaching programme on the knowledge regarding post- operative care found that the intervention was effective in improving the knowledge regarding postoperative care. The mean pre-test score was 19.8 and the post test score was 26.4 and difference in mean was significant at 0.05 level. $^{9}$

Another experimental study was conducted on evaluate the effectiveness of structured teaching programme on pre and post-operative self-care management of women who are undergoing abdominal hysterectomy. Convenient sampling technique was used to select 50 samples for the study. Knowledge of pre and post-operative self- care management among women who are undergoing abdominal hysterectomy was assessed by a structured knowledge questionnaire using structured interview schedule. The result reveals that, in pre- test, $56 \%$ of them had average knowledge and $44 \%$ of them had poor knowledge on pre and post-operative self -care management of abdominal hysterectomy, whereas during post-test $52 \%$ of them had good knowledge, $42 \%$ of them had excellent knowledge, $6 \%$ of them had average knowledge and none of them had poor and very poor knowledge. The overall mean percentage of pretest was 42.8, whereas in post-test the mean percentage was 76.63 . The difference in mean percentage was 33.83 . The paired't' value was 24.072. The study concluded that the structured teaching programme on pre and postoperative self -care management is effective among women who are undergoing abdominal hysterectomy. ${ }^{10}$

A quasi-experimental study was conducted by Seenath K $\mathrm{P}$ on effectiveness of SIM on knowledge on regime of pregnancy among primi gravid women in a selected hospital Kozhikode. The study was conducted among 60 primi mothers and sample was drawn by purposive sampling technique. The data were collected using interviewing and self-reported method. The study findings shows that the main gain in the score of knowledge was $3.567(31.8 ; 35.367)$ in control group and $83.4(30.367 ; 113.767)$ in the experimental group. The study concludes that SIM has been effective in in parting knowledge to primi gravid women on regime of pregnancy. ${ }^{11}$

The result of the present as well as the literature reviewed that pre-operative education is effective in improving the knowledge of women undergoing hysterectomy. SIM is effective strategy for improving knowledge

In the presented study selected outcome refers to the problems experienced by the women after hysterectomy namely pain, headache, fatigue, anxiety, insomnia and abdominal discomfort which are measured by 10 point visual analogue rating scale. In order to find the effect of SIM on selected outcome, the comparison of the outcomes between experimental and control group was made.
The severity of anxiety, pain, insomnia, abdominal discomfort and fatigue was less in experimental group than the control group. The mean score of the entire outcome was also significantly lower than in the control group.

Kiyohasa LY who conducted a study to evaluate anxiety levels on the day before Surgery as related to the surgery information. The Spielberg's State and Trait Anxiety Inventory (STAI) was used to measure the patients anxiety Levels. One forty nine patients were selected and interviewed. Unfamiliarity with the surgical procedure raised anxiety level $(\mathrm{p}=0.021)$. A lower state anxiety level was found among patients who did not know the diagnosis but knew about the surgery $(p=0.038)$. The study suggested that increased knowledge of patients regarding the surgery they are about to undergo may reduce their state anxiety level. ${ }^{12}$

The findings of the present study also show that the educational intervention is effective in reducing the anxiety and pain among experimental group. The mean anxiety score of experimental group was $(1.8 \pm 1.88)$.

The result of the present study as well as the literature reviewed reveals that the effect of pre-operative education was help to reduce the post-operative symptoms for a women undergoing hysterectomy.

\section{ACKNOWLEDGEMENTS}

The authors are grateful to the institutional ethical committee as well as the subjects who participated in the study. All those who provided support for conducting the study are dedicated special thanks.

\section{Funding: No funding sources}

Conflict of interest: None declared

Ethical approval: The study was approved by the Institutional Ethics Committee

\section{REFERENCES}

1. Dc Dutta. Text book of Gynecology, fifth edition: new central agency publication, page no: 564. 2012.

2. Hysterectomy. Available from URL https://www.google.co.in/webhp sourceid=chromeinstant\&ion $=1 \&$ espv $=2 \&$ ie $=U$ UTF-

$8 \# q=$ world+hysterectomy+rate $+\mathrm{in}+\mathrm{WHO}+2016$.

3. Sutton C. Hysterectomy: historical perspective, Available from: http://www.ncbi.nlm.nih.gov/pubmed/9155933. 1997;11(1):1-22.

4. Dorsey JH, Steinberg EP, Holtz PM. Clinical indications for hysterectomy route: patient characteristics or physician preference. Available from: http://www.ncbi.nlm.nih.gov/ pubmed/7503184.

5. Types of hysterectomy, hysterectomy surgical procedure, health communities'.com Available from 
http://www.healthcommunities.com/gynecologicsurgery/types-surgical-procedureshysterectomy.html).

6. Abdominal hysterectomy, Mayo clinic. Available from: procedures/abdominalhttp://www.mayoclinic.org/testshysterectomy/details/risks/cmc-20178861.

7. Postoperative care. Available http://www.surgeryencyclopedia.com/PaSt/Postoperative-Care.html.

8. George S. Conducted A descriptive study on assess the post-operative problem of patients undergoing hysterectomy in AIMS Kochi, 2014.

9. Sharmila R. Preoperative teaching about postoperative care among hysterectomy patients. Nightingale Nursing Times. 2012;8(6):62-5.

10. Kumari VJ, Jaculin. Effectiveness of structured teaching programme on pre and postoperative self- care management among women who are undergoing abdominal hysterectomy in selected maternity hospital at Bangalore. Manipal university.2012. AvailablefromURLhttps://www.google.co.in/webhp? sourceid $=$ chrome-instant $\&$ ion $=1 \&$ espv $=2 \&$ ie $=U T F-$ $8 \# q=$ pretest $\% 20$ knowledge $\% 20$ hysterectomy.

11. Seenath KP. Conducted a quasi-experimental study on effectiveness of a SIM on knowledge on regime of pregnancy among primi gravid women in a selected hospital Kozhikode. 2000.

12. Kiyohasa LY. Surgery information reduces anxiety. Brazil. 2004;59(2):151-5.

Cite this article as: Elgi MC, Lekha V. To study the effectiveness of self-instructional module on knowledge and selected outcome among women undergoing hysterectomy in a tertiary care hospital in South India. Int J Reprod Contracept Obstet Gynecol 2017;6:100-5. 